This document is the accepted version, but not the final copyright version of the article:

Leckner, S. (2015), 'The (be)coming of the book: The transformation of a text medium in the late age of print', Northern Lights 13, pp. 105-119, doi: 10.1386/nl.13.105_1.

For the final published version, please visit: http://www.intellectbooks.co.uk/journals/viewissue, $\mathrm{id}=2940 /$

\title{
The (be)coming of the book: The transformation of a text medium in the late age of print
}

\section{Sara Leckner, Malmö University}

\begin{abstract}
Digitalization has changed the preconditions for most media in recent decades, offering a rare opportunity to develop and change traditional media and the media market. The book medium is no exception. What is to be considered a book is being challenged, or, for some, threatened. As the e-book market grows there is, as with other media, still ambiguity in the direction of the development and the normalization of the e-book concept. This article discusses the extent to which physical form, genre and utilization are important when defining the book medium in the late age of print, contributing to the debate regarding the future of the book. The article is based on interviews with four prominent scholars in the research area of the digitization of text media. The findings show that, despite good arguments for how the e-book should be defined, its definition is highly context-dependent. However, as the e-book moves towards more enhanced digital versions and away from digitized ones, genre will grow increasingly important for the definition of a 'book' in the digital environment. This means that, in moving towards a more converging understanding of the future of the book, its definitions will diverge.
\end{abstract}




\section{Introduction}

A book is a book is a book. In the age of digitalization, much ink has been spilled over how the preconditions of most mass media are being affected, with no exception of the book medium. What constitutes a book is being challenged, or for some, threatened. What was new in the 1990s when the mainstream market for e-books first emerged is new no longer, and even though the market's resurgence has increased in later years, triggered by releases of special e-reading devices (starting with Sony's device in 2006) and successful business models (by Amazon in 2007), the state of the e-book remains ambiguous. While domestication has occurred to some extent in later years, and most would agree that the e-book is here to stay, this article focuses on the lack of a widely accepted consensus on what an e-book is and how this influences the development of the book medium. Since different perspectives and interests - users, authors, distributers, publishers, readers, librarians and developers - drive the development of the book market, it is easy to fall into ideological, stalled polarizations depending on one's standpoint. Although the struggle for an accepted definition may be confusing, it is nothing extraordinary in the historical development of media. The appearance of any new information technology establishes conditions for major change and it takes time before normalization occurs, often longer than imagined. In the history of the book, one example is the shift from manuscript to print, which took much longer than early studies led one to expect (Landow 2006; Ong 1982). The current competitive challenge to the book medium is not a unique occurrence in either the history of the book or its effect on society. Such challenging occurrences - often referred to as 'revolutions' (see e.g., Bill Cope and Angus Philips' The Future of the Book in the Digital Age [2006] and John Thompson's Books in the Digital Age [2005]) - have happened six times prior to digitalization, according Kilgour (1998), starting with the invention of the Babylonian clay tablet around $2500 \mathrm{BC}$. The effect of these revolutions on society, however, has been different. Although the transformation from manuscript to codex is considered to be the most fundamental so far, the transformation from codex to screen may be even more radical (see e.g., Chartier 
1995; Kilgour 1998; Svedjedal 2001). To date, the current change has primarily revolutionized the means of production, though not the product itself (see e.g., Thompson 2005). That is, the vast majority of current e-books are direct replicas of their printed counterparts - this is neither anything extraordinary in the evolution of media and the history of the book. As McLuhan ([1964] 2001) noted, we tend to consider new technologies through a 'rear view mirror', basing all that the new media are and can be on the media they are expected to replace. Comparing the digital book in direct relation to the strengths and weaknesses of the printed book therefore comes naturally. Yet, mimicking print puts constraints on the digital book since, besides being reproduced and stored on various devices, it can easily abandon a linear architecture, including digital features and adding other digital values such as streaming video and audio, comments and links, and the ability to be tagged and shared instantly. These changes affect the fundamentals of the book, both analogue and digital, and give rise to questions of what these changes imply for the future of the book as a medium. Questions related to this subject are not easy to answer; they are extendible and expandable, dependent on perspectives and interests, related to material and immaterial aspects and may change unevenly over time. And not least, they are related to the form of the book itself; some genres may have characteristics that are more easily transferable to the digital environment than others. Nevertheless, such questions are frequently asked in discussions regarding the future of the book, further touched upon in this work. This article focuses on the extent to which the physical form of the book medium is central, in relation to other properties like genre and utilization, when defining a book and an e-book, in an attempt to contribute to the debate regarding the significance of the book medium in the digital world and the becoming of the book. The rest of the article starts with an overview of the definitions of the book and e-book, followed by a presentation of interviews with four prominent scholars in the digitization of text media. Finally, the consequences on the development of the book medium are discussed and then summarized in a short conclusion. 


\section{The definition of the book}

Most people have a relatively uniform idea, albeit at an abstract level, of what a book is and how it is used. However, it is not uncomplicated to define what a book is, despite its thousands of years of history, much due to its ontological nature since the concept of 'book' holds both a concrete and an abstract meaning (e.g. Armstrong 2008; Dahlström 2005).

Commonly used definitions by, for example, encyclopaedias (Armstrong 2008) stress the book's physical entity, such as the one outlined by UNESCO in 1964, in which a book is a 'non-periodical printed publication of at least 49 pages excluding covers' (Järv and Helmersson 2015: 1). New technology, however, has also affected the definition of the book. Järv and Helmersson claim that definitions like the above may be insufficient since content can now be packaged, transmitted and presented in a variety of ways, but do not elaborate further on a newer definition. Others like Noam Chomsky and Patrick Bazin (2002, 1996, in Armstrong 2008: 194) point out that the tangible characteristic of the book can be referred to as either physical or abstract, or the two simultaneously. However, as we will see in the definition of the e-book below, some claim that the 'content' is the raison d'être of any published document at any time, and is what we implicitly refer to when we talk about the book - that is, either the abstract intellectual work or the writing (or some other system of visual symbols) (e.g. Armstrong 2008; Feather 2006). As such, the physical attributes are important only for conveying the author's thoughts to the reader. This means that a book without content should be useless other than for generating new content - for example a notebook, which, however, is considered a 'book' (e.g. OED 2014a). This also means that content elements (e.g., illustrations and text) and the number of authors should have less impact on the definition of the book than the amount of content (i.e., pamphlets and brochures are not books), the publishing frequency (nor are journals and newspapers) and the structure of the book (e.g., compare fiction with reference works). Furthermore, the definition of the book may reflect administrative aspects. Cope and Philips (2006) suggest that what separates the book from, for example, manuscripts 
and reports is its registration through the international standard book number, ISBN. However, according to the Swedish ISBN Agency, a publication does not need to have such a number in order to be considered a book (KB 2014). Moreover, the definition of the book is connected to legal aspects. The Swedish State makes a (somewhat simplified) distinction between 'products' such as printed books and 'services' like e-books and other digital reading material, by ascribing different VATs to them - 6 per cent and 25 per cent, respectively (see e.g., Snickars 2012: 227) even if the content of an e-book is an exact reproduction of the print edition. Consequently, it is challenging to define what a book is, and one may conclude that no absolute definition of the book can be established.

\section{The definition of the e-book}

If 'book' is complicated to define, 'e-book' may present even a greater challenge. In addition to the same ontological difficulty as with the printed book, the concept of the e-book is also polysemic. An e-book can denote one or more, or all, aspects of the hardware, the software and the content, whereby the content can be anything from a linear structure (like a traditional book) to an architecture consisting of isolated pieces (like a database). Similarly, the hardware can be divided into several categories (e-reader, computer, tablet, mobile phone, etc.), which in turn can use one or more different multimodalities (text, sound, moving images and so forth). Additionally, there are other definitions of digital books, such as 'audiobook', ${ }^{1}$ which may include characteristics of the e-book that are not defined as such. Hence, it is common that current definitions of e-books emphasize the book-analogy approach; an e-book is 'a digital equivalent of a printed book' (Abdullah and Gibb 2008; Helmersson 2015; OED 2014b; Swedish publishers 2008). But principally, there seem to be two main, perhaps deterministically based, standpoints that emerge when one examines existing definitions of the e-book: one focusing on physical entities and the other on content. It has been mentioned, however, that the focus on content is gaining ground (e.g. Westöö-Olsson 2008). For example, in 2009 the Swedish 
encyclopaedia Nationalencyklopedin (see also e.g. Dahlberg 2009; Henke 2002; Svedjedal 2001) defined the e-book as a 'hand-held computer with integrated software, specifically designed for the reproduction of digitally stored texts, with or without sound'2 (Leckner 2009: 134), while in 2015 they, along with other sources, describe the e-book as a digital file suitable to be read on a computer device (Helmersson 2015). Those who find it important to distinguish between content and technology (e.g. Abdullah and Gibb 2008; Armstrong 2008; Garrod and Weller 2005) interpret the technology to denote the tool (often the hardware) used to access the content, termed 'e-book reader' or similar, primarily denoting a digital device with characteristics similar to a printed book (see e.g., Leckner 2007) but which can also mean a personal computer or mobile phone. The term 'e-book reader' has also been used to refer specifically to the software used to access the content by, for example, Swedish e-book distributers and libraries (Leckner 2009), although this is currently often changed to 'reading program'. However, some definitions explicitly or implicitly include both content and technology (e.g. Lynch 2001; OED 2014b), which is also claimed to be the original intention of the definition of the e-book (Abdullah and Gibb 2008).

In respect to the focus on content, the definitions include two types of content that (1) is or (2) is not written for the digital medium. (1) refers to e-books that are digital replicas of the file used to produce the printed book (i.e., digitized content), primarily designed to be read linearly with no or few digital value-added material; that is, on-screen the document looks just as if it were written on paper. (2) embraces the definition of so-called 'enhanced e-books' (e.g. Renman Claesson 2012; Warnqvist 2012). Such e-books include hypertextual and digital features, and may retain their 'book-ness' to a lesser extent. In the definition relating to (1), replacement is always required, affecting the experience compared to the print version. Included in the lost dimensions is virtually every aspect of the printed medium's spatial materiality (e.g. Dahlström 2005). Content in (2) is text that is either 'born digital' or primarily intended for publication on a digital text carrier, thus noticeably different compared to the printed version. 
However, semantics can be challenging here; what distinguishes an e-book from a website or a database? Legal requirements can exist for how a database should be defined, but the legal definition of a database may not be the same as its technical definition. This especially relates to digital content with different linearity, layout or shape compared to a traditional book, such as reference or digital works. For example, libraries have termed digital works designed to be read from cover to cover as e-books, while encyclopaedias and reference works are designated as databases (Leckner 2009; Westöö-Olsson 2008). Meanwhile, other digital text forms (e.g., blogs, communities, chats) may show similarities to the definition of an e-book. Wikipedia, for instance, has been suggested to be a subgenre of an e-book, termed a social book (like, e.g., a blog) or a network book (Armstrong 2008). Thus, the problem with defining an e-book is the same as for the printed book, yet even more complex due to the variety of forms, formats and features available. Therefore, following Gibson and Gibb's (2011: 307) definition - a simplified version of the definition proposed by Vassiliou and Rowley (2008) - might be an easy way out: an e-book is 'a digital object that is recognisably book-like'.

\section{The development of the book medium; interviews with scholars}

Since the e-book will become increasingly important as a carrier of text, but is currently at a stage between pure novelty and normalization, it is useful to get further perspectives on the complexity of the development of the book medium and its definitions. For this purpose, interviews were carried out with scholars whose research targets the digitization of text media, elaborating on these aspects. Using a strategic sampling method, six researchers were selected from the Scandinavian countries. The selection was based on the author's own geographic area and on the prominence of scholars related to the subject in these countries. Of six consulted scholars, four participated in the interviews: Mats Dahlström, University of Borås, Swedish School of Library and Information Science (Sweden); Martin Engebretsen, University of Agder Department of Nordic and Media Studies (Norway); Terje Hillesund, University of Stavanger, 
Department of Media, Culture and Social Sciences (Norway); and Sören Pold, Aarhus University, Department of Aesthetics and Communication (Denmark). The scholars were first contacted in 2009 for another study (Leckner 2009), but had the opportunity to update their answers for this article. The interviews, conducted via e-mail, consisted of fourteen questions on three themes related to the development of the book medium and its future: definitions of the book medium, the impact of genres, and utilization of digitized and digital text.

\section{Definitions of printed books versus e-books - what a 'book' is}

What defines a book is not an easy question to answer. According to Dahlström, the answer is that it is context-dependent and phenomenological; that is, a book is what people perceive a book to be. Dahlström suggests that, roughly speaking, there are three definitions to a book: (1) the substantive understanding: a book is an object that has a material structure - a physical concept that is often found in the history of the book. It is not tied to codex, since the definition can include scrolls, clay tablets and so forth; (2) the equivalence of book and work: the author does not produce the physical book (the printers do this), but rather the content. In this sense the book is the intellectual work, not the material object itself. This definition is useful when examining the understanding of the e-book; and (3) the book is the text that can fit in a physical copy. For example, both the Iliad and the Bible contain a number of 'books', but this ancient definition of the book refers to the amount of text that could fit into the contemporary text-containing volume - for example, the scroll. Dahlström continues that, when one ventures to define or understand the concept of the e-book, the last two definitions surface. An e-book can be a material object, but can also abstractly refer to the work, to the amount of text that corresponds to a printed book, or to the software itself. For example, 'Yesterday I bought Guillou's e-book, which I'll read in my e-book using Microsoft's e-book'. However, currently an e-book is often referred to as the text or book corresponding to a printed book. The role of content and genre in the general definition of a book, Dahlström asserts, depends on which definition of e-book one uses. In the 
first definition, content and genre play a minor role: it can be a completely blank book, perhaps a notebook, whereas in the second definition the content in relation to genre is more interesting. Yet, according to Dahlström it is hard to say whether content and genre play decisive roles, although perhaps somewhat more so in genres like fiction. Dahlström continues that the characteristics of the printed book are that the storage medium and presentation medium coincide, and that they have a fixed order, are often sequential, support spatial overview, and may be conducive to more intensive reading. The digital book has the characteristics that the storage and presentation medium are separate, which provides more opportunity to rearrange the content, and that they are often multi-sequential, support search functions, and may be conducive to more extensive reading. However, Dahlström asserts that dictionaries and reference works are examples of printed books that do not follow the characteristics above and were hence early to make the transition into the digital format, and, correspondingly, nor does a digital PowerPoint presentation. ${ }^{3}$ But a copy of a printed book can work as a vade mecum and have both a symbolic and a social value that differs from that of e-books. For example, spatial perception is quite different in the two realms.

Engebretsen considers a book to be a printed medium that forms its content in a certain way, usually in chapters and subchapters, and that possesses certain general characteristics expressed through static modalities such as writing, pictures and graphics. The content is of a size and character that requires many pages and has a lasting value, and therefore must be given a relatively solid 'body wrap', unlike advertisements, for example. An e-book on the other hand is not a book by definition but a typical manifestation of the traditionalism that characterizes the early phase of each remediation process. Thus, independent of what text is transferred and how this is done, a digitized book is not a book in the traditional sense. Engebretsen claims that, instead of an inclusive e-book concept, it may be more relevant to break it down into individual genres: e-novel, e-poetry, e-encyclopaedias and so forth. Such content/genres are characterized by one or more of the characteristics of digital media: large 
storage capacity, searchability and hyperlinks, which in turn support non-linear content organizing, multimedia expressions, and design that promotes interactivity - between users, user and content, and user and system.

Hillesund has two different views on the definition of the book. In print the book concept is connected to codex, while digitally it is linked to the length of the text. Coherent, long digital texts are e-books, while online encyclopaedias, for example, are not. Contradictorily, print encyclopaedias published as a digital unit are an exception and may be regarded as books if installed on specific e-book readers. Thus, according to Hillesund, the print book is characterized by being a physical object, with its text fixed on a two-dimensional surface. It is tactile, easy to browse and highly navigable if the text uses the medium properly - that is, through headings, page count, captions, etc. Moreover, it is relatively lightweight and portable. From a purely material point of view an e-book is not a book, but when regarded as text it is. However, there are differences between various types of e-books and thus how they are characterized, according to Hillesund. He asserts that on the one hand there are e-books indented to be read digitally. These books are flexible in their presentation and allow the reader some freedom in choosing the layout and font size. Presented in designated devices such as e-readers, these e-books are very reader-friendly and functional but lack the navigability of the printed book. On the other hand, there are digitized books, primarily indented for print in formats such as PDF. These e-books are less suited for reading on e-readers and have poorer visibility on a computer display. Finally, Hillesund states, there are encyclopaedias, manuals and similar works remediated to digital form, which are highly searchable and functional and are suitable for e-readers. All e-books are characterized by their virtual text, requiring little physical storage, movable over networks, and often with specific link structures and flexibility in their presentation. According to Hillesund, genre is relevant when defining the book in the digital world but not in the printed one. Thus, in the digital environment the concept of the book will be reserved for coherent works, while forms using hypertext and digital media features will no longer be called books. 
Pold agrees with Dahlström that the definition of the book depends on situation and context. Codex is a highly flexible form but is normally characterized by particular aspects such as author, title, structure, number of pages, etc. (see also the description by Engebretsen, above), but not necessarily all these things every time. An e-book is a book in that it simulates some of these properties. According to Pold, genre means a great deal for the definition of the book. For example, Pold continues, there is a huge difference between a non-fiction book, a reference book and a novel. The former can in principle be changed functionally, while changes in fictional genres will have substantive and symbolic consequences. With the current fluidity of the media landscape, Pold asserts, the book medium is affected and thus the boundaries between different genres will become increasingly blurred.

\section{Book genres and their impact on the definition of the book medium}

The respondents agree that, generally speaking, all current book genres fit the digital environment. Engebretsen elaborates that the genres that fit the digital form are those that require one or more media attributes - for example, a large database for comprehensive amounts of content that is searchable and user-controlled and has a non-linear content organization. Thus, the vast majority of the existing print genres are appropriate for digital formats. Least suited are probably the genres with a linear representation and a strong foundation in the print medium, such as novels, short stories and debate books. Hillesund, on the other hand, believes that fiction may be the genre that best suits the digital format. Of all the literature genres, Hillesund claims, only the novel can be transferred directly to a digital format, if adapted for devices such as ereaders, with flexibility added to the presentation and if the static PDF format is avoided. This would be true of encyclopaedias as well, if they were adapted to computer screens. Genres like educational books and non-fictional books, Hillesund continues, are least suitable for the digital environment, since they require a combination of continuous reading and navigation, which print currently provides in a better way. The computer screen is currently best suited for discontinuous 
reading, for the search and pursuit of links, while the e-reader is best suited for the continuous reading of longer texts, according to Hillesund. However, Hillesund continues, non-fictional books have great potential digitally, particularly in terms of readability and linkability. Dahlström claims that genres like poetry (in its very traditional meaning) 'fit' the characteristics of print, whereas genres like library indexing exhibit properties that match those usually attributed to digital media. This, Dahlström continues, is why library indexing is among the genres that have almost completely been digitized. Pold adds that non-fiction fits digitization based purely on functional criteria, whereas fictional genres can more advantageously explore digital forms, currently seen in net art, digital literature and interactive fiction.

All the respondents believe that there are genres (not necessarily all 'book' genres) that only exist digitally, such as instant messaging, online games, websites, discussion groups, online encyclopaedias and search engines. But they also assert that the boundaries between old and new genres can be difficult to define, such as the blog, which can be said to be a true child of network media but is actually akin to the diary. Other examples of new genres are hyperworks (although these may be more of a scientific study object rather than commercially realized products), digital poetry (perhaps the fictional genre that best utilizes digital properties) and digital text-critical archive editions.

\section{The utilization of digitized and digital text}

The way codex should be transferred digitally depends on object and context, according to the respondents - for example, whether one uses the technology to digitize the text or to develop and modify its form and function. Engebretsen points out that changing a linear text to a hypertextual, multimedia-interactive one is a very complex issue and that weird things may happen. Dahlström exemplifies this with the digitization of T. S. Eliot's 'The Waste Land', in

which implicit allusions were turned into explicit hyperlinks. Implicit allusions trigger the reader's thoughts, as opposed to direct links to the source; thus, some of the intended ambiguity 
of the original allusion disappeared, making it artistically different. Dahlström points out that the choice of which textual components are included in the transfer from one medium to another also varies, and thus that the impact of the transfer on the context and the reading experience will also vary. Text components such as footnotes and maps may not be transferred correctly and some print qualities cannot be transmitted at all, at least not today. Dahlström points to Raymond Queneau's One Hundred Thousand Billion Poems [1998], in which the poems in the printed edition are printed on separate strips and can be composed in 'one hundred thousand billion' ways depending on how the reader physically arranges the text. When the book was digitized, it was made into a database with a random-number generator. Medially, according to Dahlström, this makes it a completely different work, for better or worse.

Hillesund asserts that less realization is required with books based primarily on text, such as novels and scholarly works, when creating for a digital format. With genres like educational books one may need to think in a more multimodal way and collaborate with photographers, video producers and web designers. On the whole, design thinking comes to be central in the digital world. The 'story' will be largely the same, but as digital properties make impressions on genre and story, the writing will change, sometimes dramatically. Hillesund continues that, with text intended for continuous reading, the flow should not be destroyed by too many choices (e.g. links) or other types of information (images, video, audio, etc.), while relatively short text sequences (e.g. educational materials and non-fiction) offer greater opportunities for the use of digital properties. However, Pold adds, in the digital format a schism often occurs between the ergodic interaction and the fixed text, which will affect the forms of the work and thus the experience. Dahlström points out that many genres should utilize, and would benefit from exploiting, digital properties more, such as the non-fiction genre. However, it is sometimes important to stay as close to the original as possible in digital form in order to maintain the spatial properties, in which there are many symbolic and social values. Here, static formats like the PDF work well. 


\section{The future of the 'book'}

What is the future of the book? None of the respondents believe that codex as a text carrier will become extinct. However, generally, they believe that if literature as an institution, as well as the book industry, is to remain relevant and competitive in the future, the book medium has to adapt to the digital environment. They claim, however, that the adaptation of media, content and users to digitization is a slow process, but that eventually the book medium will change and new media technologies will conquer certain genres. According to Dahlström, it is likely that any genre that is markedly characterized by features supported by print will resist digitization, and vice versa. Engebretsen exemplifies this by proposing that the long, well-written essay suits the print medium, whereas large amounts of searchable information fit digital media better. However, Dahlström argues, both digital and analogue properties may be required in a work; thus, a genre does not have to be simply either print or digital. It is a matter of evolution, whereby forms change depending on various factors, and both old and new forms live on and evolve in an ecosystem. This means that all genres may change with time, Pold adds. One can imagine entirely new genres or cross-genres, according to Dahlström - for example, between film and literature (something that already can be found in computer games). Thus, digital properties will be utilized much more in the future, a utilization that Dahlström asserts has been underestimated in the long term. Hillesund adds that the effect of cultural delay should be taken into account, as should the clash of generations; give the digital book 30 years, and the book market will look entirely different. Hillesund concludes that how the book medium, literary institutions, authors and readers deal with this change is critical for the future of the book.

\section{New forms and conceptualizations; discussion on the becoming of the book}

According to previous sections the book, as well as the e-book, consists of three elements: the

work, the content and the presentation medium. ${ }^{4}$ A book does not have to be synonymous with its content (see also Bolter 2001; Svedjedal 2001). Another way to express this is that a book is 
not necessarily an object but a textual form, a way to communicate, and a form of information architecture (see also Cope and Philips 2006). In this sense, both a printed book and an e-book can be defined as 'books'. An e-book can be a book in the sense that it simulates some of the flexible properties of codex. On the other hand, today the word 'book' may be insufficient because the concept can accommodate very different types of structures and genres. In reference to the concept 'e-book', the acronym 'p-book' has been suggested for printed books, currently in use to some extent in, for example, Anglo-Saxon countries (e.g. Striphas 2011). Furthermore, it can be more relevant, as also pointed out in the interviews, to break down the definition of ebooks into individual genres, such as e-encyclopaedias and e-poetry, when moving away from the resemblance to codex. Relevant cases are when a work is originally created digitally, when the digitized version has been 'enhanced', and when the characteristics of codex put constraints on the digitized content (see also Dahlberg 2009). This also means, as pointed out by Pold in the interview, that the boundaries between current genres will become increasingly blurred.

However, 'book-ness' is currently what makes a digital book a 'book' in the substantive sense. It is also what distinguishes the e-book from other digital 'books' - for example, audiobooks - since a 'book' today can be represented through different modalities handwriting, print, audio, digitally - but, as pointed out in the interviews, not without new formal arrangements for how the content is presented, and thereby modifications to the perceptions and interpretations of the content (see also Bolter 2001; Chartier 1995; Dahlström 2005; Leckner 2007). In relation to each medium's normalization process, a typical media textuality is formed for each (text) medium over time. Dahlström (2005) exemplifies this with the particular characteristics of the scroll that have been maintained in the subsequent codex. However, the textuality of the scroll is also apparent in digital media, with properties that have passed through codex (e.g. the column) or have detoured around it (e.g. scrolling) (Dahlström 2005). It would be a genuinely new medium if its characteristics could not be traced to any older media, but this does not seem possible in our culture (Bolter and Grusin 2000). As such, as 
pointed out by Engebretsen in the interview, the current e-book is a typical manifestation of the traditionalism that characterizes the early phase of each remediation process.

The strength of our connection to codex can be seen in the relatively few books that have been produced specifically for the digital format, especially in genres like fiction, compared to the many more that have been digitized. What does this mean in practice? The printed book is largely associated with the reading model that is applied today, whereby for example fiction is something quiet and linear running from the first to the last page - something also mentioned in the interviews - established when the mass-produced novel was born in the eighteenth century (e.g. Svedjedal 2001). The current conceptualizing of the e-book as a 'book' is greatly connected to these structural, monosequential characteristics. As such, as argued by Chartier (1995), the concept of text has yet to break loose from the axiom that lets us associate it with a certain form of container (see also Derrida and Barthes in Landow 2006: 2). Whether or not the concept of the e-book is born out of the need to overcome the limitations of paper, most e-books contain features that would not have been possible on paper. ${ }^{5}$ Since the e-book, already in its simplest form, can expand the text in a way print cannot, for several years now many people have imagined that the e-book as 'a digital equivalent of the printed book' will not be the primary conceptualization for long (e.g. Renman Claesson 2012). Digital text can be released from codex, via hypertext and other digital features, which partly creates new expressive possibilities and partly redonates narrative qualities that the linearity of the traditional book has limited (e.g. Bolter 2001; Landow 2006). Examples of recent commercial experiments with the book medium are files and apps constructed more like card indexes than pages, including dramatized sequences, audio readings and other interactive features, particularly in genres like lyricism and education (Borg 2014). However, one can criticize the stubborn dichotomization between paperbased and digital text, in which the representation of the media forms is often based on their differences and contradictions rather than their synergetic effects. On the contrary, there may be more similarities between digital and analogue text than between genres within the same format 
(see also e.g. Aarseth 1997). As Foucault writes, the 'frontiers of a book are never clear-cut' because 'it is caught up in a system of references to other books, other texts, other sentences: it is a node within a network...' (1976: 23). For example, as also pointed out by Svedjedal (2001), it is difficult to read printed texts without encountering things such as hypertext or at least hypertextual elements. Examples of how non-linear and/or interactive narrative can be achieved in different ways in printed books include pop-up books (e.g. Sara Fanelli's The Onion's Great Escape [2012]), works without a traditional beginning or end (e.g. James Joyce's Finnegan's Wake [1939]), or works with implicit allusions (e.g. T. S. Elliot's 'The Waste Land'). Such works are not necessarily easier to transfer to the digital environment, as pointed out in the previous section. Changing a linear text to a hypertextual, multimodal interactive one is a very complex issue, and regardless of genre strange things may happen, as also illustrated in the previous section. However, as pointed out in the interviews, some genres fit the digital environment better and are thus more easily transferred or transformed. Nonetheless, according to the respondents, many genres would also benefit from exploiting digital properties more, whereas sometimes it is important to stay as close to the print original as possible in order to maintain symbolic and social values.

Thus, features ascribed to the digital environment are not new or revolutionary types of text with opportunities only available digitally. The reverse is also true: just because digital media enables more multi-sequential hypertext, this does not mean - as is well known that all digital documents are hypertextual. The fundamental difference, however, is the openness of digital media as antithetical to the printed book medium's closed universe (see Snickars 2012). The digital text is always (more or less) dynamic and extendable, whereas the printed work consists of a delimited, determined amount of text (see also Dahlberg 2009; Snickars 2012), concreted on the page, in a way that has been characterized as 'passive' (see e.g. Svedjedal 2001: 52). For better or worse, the fluidity of digital text makes it both more 
'innovative' as well as more uncertain regarding structure and consistency. This is why it is likely that codex and digital text forms can coexist.

\section{Concluding reflection}

Based on the content of this article, it is not possible to find one unified definition of the e-book or what the development of the e-book will become. On the contrary, the definition of the e-book is highly context-dependent - it can mean the work, the material content, the software and/or the hardware, or combinations and subcombinations of these - mirroring different interest groups' interests and perspectives, as also shown in the interviews. Meanwhile, the e-book definition seems to lean towards 'content' as opposed to technology, although 'content' per se can mean different things. Therefore, it seems likely that the e-book concept will evolve towards different e-book genres with different definitions, whereby each solution and genre will have to make different sacrifices in terms of similarities to codex, since no e-book format will fit all situations, contents or persons. This course of evolvement is dependent not only on the readers, writers and literary institutions (as suggested in the interviews), but particularly on powerful market-leading IT companies and retailers (e.g. Amazon, Apple, Google), setting the agenda for the future of the book with regard to innovative digital e-book technology and economy (e.g. Snickars 2012). These conglomerates are not related to book publishing in any traditional sense, but are today greatly impacting on standardization, copyright and competitiveness on the book market. For good and bad, these companies not only have the power to drive the development in an innovative way but can also put constraints on it through, for example, standardizations that favour themselves and not the development of the book as such.

Although we might not have to wait 30 years for the book market to look totally different, the predicted powerful 'break' for e-books has yet to come. Meanwhile, discussions arise about the coming of the 'book', based on different ideological and polarized standpoints, sometimes characterized by dichotomized opinions between the old and the new - print and 
digital media - in relation to the becoming of the 'book'. Piper puts his foot down on this ideological schism, claiming that

Books will always be there. Whether in the classroom, the library, the archive, the bookstore, the warehouse, or online, it is our choice, however, where books will be. It is time to stop worrying and start thinking. It is time to put an end to the digital utopias and print eulogies, bookish venerations and network gothic, and tired binaries like deep versus shallow, distributed versus linear, or slow versus fast. Now is time to understand the rich history of what we have thought books have done for us and what we think digital text might do differently. (2012: xi, original emphasis)

As Ong argues, 'the technology of writing' is one way to change the dynamic sound to a static surface, regardless of whether the tool is cowhide and stone, parchment and brush, or computer and binary coding (1982). However, how the tool is constructed will certainly affect the shaping of the 'technology' (e.g. McLuhan [1964] 2001).

So is the e-book the last book? Just as the printed book has pushed its predecessors into marginalization, print may be pushed out of its function as the main carrier of text. Most scholars agree that print books will not disappear completely (see also e.g. Bolter 2001; Svedjedal 2001), at least not for a long time, since codex holds many advantageous characteristics that are difficult to simulate in the digital environment. Rather, the development is much more ecological in nature: how will these two very different forms and their many varieties coexist within the greater ecosystem known as reading (see also Ong 1982; Piper 2012)? As has been pointed out, both digital and analogue properties may be required in a work and thus a genre does not have to be either print or digital, whereby the qualities with strong connections to codex will resist digitalization and vice versa. This also means that the boundaries between old and new genres will become more difficult to define, as part of the remediation process (e.g. 
Bolter and Grusin 2000; McLuhan [1964] 2001; Ong 1982).

The current ambiguity of the e-book and its potential development, however, is constructive in that it allows us to see concepts like text, book and work with fresh eyes. Here, when we define the new, it is convenient to use the past as a reference - however, also everything current that lends itself to what is not. A major criticism of the current e-book concept has been its static replication of the printed book. Ironically, when the e-book loses its 'bookness' is precisely when it will no longer be called a 'book'.

\section{References}

Aarseth, E. (1997), Cybertext: Perspectives on Ergodic Literature, Baltimore: Johns Hopkins University Press.

Abdullah, N. and Gibb, F. (2008), 'Students' attitudes towards e-books in a Scottish higher education institute: Part 1', Library Review, 57:8, pp. 593-605.

Armstrong, C. (2008), 'Books in a virtual world: The evolution of the e-book and its lexicon', Journal of Librarianship and Information Science, 40:3, pp. 193-206.

Bolter, J. D. (2001), Writing Space: Computers, Hypertext, and the Remediation of Print, 2nd ed., Mahwah: Lawrence Erlbaum Associates.

Bolter, J. D. and Grusin, R. (2000), Remediation: Understanding New Media, 2nd ed., Cambridge: MIT Press.

Borg, A. (2014), 'Digitala experiment spränger bokmediet'/‘Digital experiments blast the book medium', Svenska Dagbladet, 14 January, p. 25.

Chartier, R. (1995), Forms and Meanings: Texts, Performances, and Audiences from Codex to Computer, Philadelphia: University of Pennsylvania Press.

Cope, B. and Philips, A. (2006), 'Introduction', in B. Cope and A. Philips (eds), The Future of the Book in the Digital Age, Oxford: Chandos Publishing, pp. 1-18. 
Dahlberg, L. (2009), 'Från boksida till Facebook'/‘From book page to Facebook', in Nordiska digigruppen (ed.), Författaren $i$ den digitala tidsåldern: en studie beställd av den nordiska digigruppen/'The author in the digital age: a study commissioned by the Nordic digigroup', Stockholm: Sveriges författarförbund, pp. 91-182.

Dahlström, M. (2005), 'På vilken fråga är e-boken ett svar? Del 1'/'What question does the ebook answer? Part 1', Ikoner, 3, pp. 42-53.

Feather, J. (2006), 'Access, convergence and print on demand: The library dimension', in B. Cope and A. Philips (eds), The Future of the Book in the Digital Age, Oxford: Chandos Publishing, pp. 177-89.

Foucault, M. (1976), The Archaeology of Knowledge and the Discourse on Language, New York: Harper and Row.

Garrod, P. and Weller, J. (2005), 'Ebooks in UK public libraries: Where we are now and the way ahead', UKOLN 2, http://www.ukoln.ac.uk/public/nsptg/e-books/. Accessed 2 May 2015.

Gibson, C. and Gibb, F. (2011), 'An evaluation of second-generation e-book readers', The Electronic Library, 29:3, pp. 303-19.

Gunder, A. (2004), 'Hyperworks: On Digital Literature and Computer Games', Ph.D. thesis, Uppsala: Publications from the Section for the Sociology of Literature at the Department of Literature, Uppsala University.

Helmersson, D. (2015), 'e-bok', Nationalencyklopedin, http://www.ne.se/uppslagsverk/encyklopedi/lång/e-bok. Accessed 2 May 2015.

Henke, H. (2002), 'Survey on electronic books features', http://www.openebook.org/. Accessed 18 May 2015.

Järv, H. and Helmersson, D. (2015), 'Bok', Nationalencyklopedin, http://www.ne.se/bok/132314. Accessed 20 May 2015.

Kilgour, F. G. (1998), The Evolution of the Book, Oxford: Oxford University Press. 
Kungliga Biblioteket (KB) (2014), 'Vanliga frågor om ISBN'/'Frequently asked questions about ISBN', http://www.kb.se/isbn-centralen/isbn/fragor/. Accessed 2 April 2015.

Landow, G. P. (2006), Hypertext 3.0: Critical Theory and New Media in an Era of Globalization, 3rd ed., Baltimore: Johns Hopkins University Press.

Leckner, S. (2007), 'Is the medium the message?: The impact of new media on the newspaper concept', doctoral thesis (Trita-csc-a 2007:17), Stockholm: Royal Institute of Technology. (2009), 'Boken som medium: Bokformatets betydelse i den digitala världen'/'The book as medium: The importance of the book format in the digital world', in Nordiska digigruppen (ed.), Författaren i den digitala tidsåldern: en studie beställd av den nordiska digigruppen/'The author in the digital age: a study commissioned by the Nordic digigroup', Stockholm: Sveriges författarförbund, pp. 129-81.

Lynch, C. (2001), 'The battle to define the future of the book in the digital world', First Monday, $6: 6$.

McLuhan, M. ([1964] 2001), Understanding Media: The Extensions of Man, London: Routledge. Ong, W. (1982), Orality and Literacy: The Technologizing of the Word, London: Methuen and Co.

Oxford English Dictionary (OED) (2014a), 'book, n', OED Online: Oxford University Press, http://www.oed.com/viewdictionaryentry/Entry/21412. Accessed 20 May 2015.

_ (2014b), ‘e-book, n’, OED Online: Oxford University Press, http://www.oed.com/viewdictionaryentry/. Accessed 20 May 2015.

Piper, A. (2012), Book was There: Reading in Electronic Times, London: The University of Chicago Press.

Renman Claesson, K. (2012), 'Boken, författaren och läsaren. En upphovsrättslig reflektion'/'The book, the author and the reader. A copyright reflection', in U. Carlsson and J. Johannisson (eds), Läsarnas marknad, marknadens läsare/‘The readers' market, the market's 
readers', Göteborg: Nordicom, Göteborgs universitet, pp. 241-48.

Snickars, P. (2012), 'Boken som medium'/'The book as medium', in U. Carlsson and J. Johannisson (eds), Läsarnas marknad, marknadens läsare/'The readers' market, the market's readers', Göteborg: Nordicom, Göteborgs universitet, pp. 221-30.

Striphas, T. (2011), The Late Age of Print: Everyday Book Culture from Consumerism to Control, New York: Columbia University Press.

Svedjedal, J. (2001), Den sista boken/'The last book', Stockholm: Wahlström och Widstrand.

Swedish publishers (2008), Ljudböcker och e-böcker på The Pirate Bay: En kartläggning av illegal fildelning/'Audio books and e-books on The Pirate Bay: A survey of illegal file sharing', Stockholm: Svenska Förläggareföreningen.

Thompson, J. B. (2005), Books in the Digital Age, Cambridge: Polity Press.

Vassiliou, M. and Rowley, J. (2008), 'Progressing the definition of "e-book", Library Hi Tech, 26:3, pp. $355-68$.

Warnqvist, Å. (2012), 'Dragonball, LasseMaja och Twilight'/'Dragonball, LasseMaja and Twilight', in U. Carlsson and J. Johannisson (eds), Läsarnas marknad, marknadens läsare/'The readers' market, the market's readers', Göteborg: Nordicom, Göteborgs universitet, pp. 295-314. Westöö-Olsson, H. (2008), 'Det hybrida biblioteket: Synliggörande och integration av e-böcker vid akademiska bibliotek'/'The hybrid library: Visibility and integration of e-books in academic libraries', master's thesis, Uppsala: Uppsala Universitet.

\section{Contributor details}

Sara Leckner received her $\mathrm{PhD}$ in 2007 in Media Technology from the Royal Institute of Technology in Sweden. She is currently working as a Senior Lecturer at the department of Media Technology and Product Development at Malmö University in Sweden. Her research focuses on 
new media devices and services, multiple-channel publishing, media management, usability, and new media theory.

Contact: Department of Media Technology and Product Development, Faculty of Technology and Society, Malmö University, 20506 Malmö, Sweden.

E-mail: sara.leckner@mah.se

Notes

${ }^{1}$ Compare, for example Swedish Publishers' definition: e-book, a book in digital format that can be read via a digital medium, such as on a computer screen or mobile; CD-book, audiobook sold in hard copy on a CD; audiobook, a book recorded onto a digital medium, usually sold as a CD or digital audio file (MP3); (Digital) Work, CD-book, audiobook or e-book (2008: 11).

${ }^{2}$ This is one effect of the dynamic fluidity of digital text. Since the source has been updated since 2009, it is not possible to find the original reference for this quote.

${ }^{3}$ See also Gunder (2004), who defines the distinction between storage and presentation media in Hyperworks: On Digital Literature and Computer Games.

${ }^{4}$ Presentation and storage medium may be separated in e-books, however.

5 For examples of digital and analogue characteristics, see Dahlström (2005: 49-50) and Armstrong (2008: 198). 